structurally like Siderastroea, but simple. The other, Barbadiastroea, is probably a faviid.

Wells discusses the probable temperature and depth conditions under which the coral fauna lived. $\mathrm{He}$ rightly concludes that the evidence favours "a tropical shallow-water, but not littoral, environment", and suggests "a depth at or beyond the minimum temperature $\left(21^{\circ} \mathrm{C}\right.$.) necessary for vigorous growth of reef corals, which is now approximately 75 metres in the Windward Islands, with a maximum of nearly 200 metres elsewhere in the West Indies".

The two species of Miocene corals from Martinique are interesting. One belongs to Eusthenotrochus, a peculiar sub-genus of Sphenotrochus, hitherto known only from a Recent South African species and from an Eocene species from the Paris Basin. Wells notes an undeseribed specimen, probably identical with his new species, from the Miocene Bowden marl of Jamaica. The other species, Dominicotrochus dominicensis (Vaughan), occurs in numbers enabling its range of variation to be determined. It also suggests that Vaughan's original, ill-localized specimen from the Dominican Republic is also of Miocene age.

H. Dighton Thomas

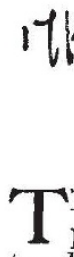

\section{FOOD AND AGRICULTURE ORGANISATION}

$\mathrm{T}$ HE report of problems Armmoned by the Food and Agricultural Organisefion of the United Nations at Washing. ton dun Nay 20-27, 1946, as a sequel to a resofution of the General Assembly on February 11, incluks an appraisal of the world food situation during 1946-47, issued on May 14, 1946 (Washington : Food and Agricultural Organisation). This emphasizes that a critical world food shortage will continue at least until crops are harvested in 1947, even assuming average or somewhat better than average weather for the rest of 1946 and 1947. In spite of some prospective increases compared with 1945 in both Continental Europe and the Far East, production in 1946 in continental Europe generally as well as rice production in the Far East will still be well below the pre-war level. World stocks of food have been seriously depleted to meet the current crisis, and the incidence of any widespread drought in the months immediately ahead might well be even more disastrous than the effects of the droughts which developed in 1945 and early in 1946 .

As regards Continental Europe, the report points out that, even if the production estimates are realized, imports equivalent to about 16 million metric tons of wheat would be required to bring the average consumption to about 90 per cent and of French North Africa to about 95 per cent of the pre-war level. Assuming that sufficient meats, fats and oils, and sugar were available to bring consumption for these commodities to about 80 per cent of the prewar a head level, some $12 \cdot 5$ million metric tons or 450 million bushels of wheat would be required. Moreover, even with imports at this volume and average consumption at a level ranging from 2,250 calories a head daily in the European-Mediterranean area to 2,550 calories or more in Western Europe, non-farm consumption in some countries would still be under the emergency subsistence level. The urban food situation over wide areas in Continental Europe will thus again be disastrous in the spring of 1947 unless livestock feeding is held to a minimum and supplies are evened out as between different consumer classes and over the year.

The situation in the Far East is equally serious. With average yields the production of paddy (unhusked) rice may be 7 per cent higher than in 194.5, but the bulk of this rice will not be harvested until November onwards, and estimates are still 10 per cent short of the pre-war level. Even under favourable conditions, not more than 2.5 million metric tons of paddy is expected to be available for shipment, as against 10 million metric tons in the pre-war period 1935-39. Current reports indicate that the wheat and other grains crops harvested in India are short; and so far as can be estimated, some 25 million tons (wheat equivalent) of cereals or other staple foods would be required to raise Far Eastern diets even to their full pre-war level in 1947-diets which themselves were usually too low for promoting health and working efficiency.

Discussing the export situation, the report notes that supplies are unlikely to be greater in 1946-47 than the amounts actually moved in 1945-46 unless effective measures are taken to reduce the amounts used in the exporting countries. Supplies of wheat are likely to be smaller, and of fats and oils no greater than in 1945-46. Supplies of cane-sugar available for shipment should be about 20. per cent greater, but supplies of meat and manufactured dairy products from the Americas, Australia and New Zealand are unlikely to be any greater. On the other hand, it is anticipated that fish production in 1946-47 will be substantially greater than in 1945-46. Fertilizer supplies are likely to be short in every major producing area, and in very large areas agricultural rehabilitation is necessary to achieve production possibilities.

The survey is completed by a summarized report from the Nutrition Committee which puts the emergency calorie intake requirements at about 2,200 a head daily at the retail level to prevent sections of the population from falling below the danger point. This level may be somewhat lower in eastern and tropical countries generally.

This appraisal provides the basis on which the special meeting during May 20-27 of the Food and Agriculture Organisation framed its recommendations. Those of its first committee related to the establishment of a Research and Information Service to provide the Organisation with further appraisals, to help keep the situation under review, and assist the International Emergency Food Council with information in the same way. Detailed recommendations from the Second Committee, on the Conservation and Expansion of Supplies, include extraction-rates of at least 85 per cent for wheat and rye in all countries for the consumption year 1946-47, and further curtailment of the use of wheat and other grains for feeding animals, as well as proposals for increasing the supplies of food products from the 1947 harvest, covering fertilizers, seeds and equipment. A further section of this report deals with principles and policy to be adopted by individual countries and by the International Emergency Food Council in regard to the production, collection, procurement, allocation and distribution of foodstuffs; if the measures recommended are adopted forthwith and applied consistently throughout 194647 , a repetition of the hardship and privation of 1945-46 can largely be avoided. The report of yet a third committee is concerned with future machinery; 
in addition to recommending close co-operation with U.N.R.R.A., it recommends the establishment of an International Emergency Food Council and a survey of existing organisations dealing with long-term problems with the view of providing any further international machinery required.

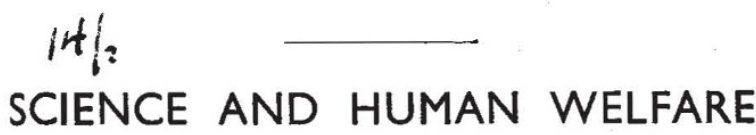

A REPORT of thoroceedings of the conference, A spongored Wy the Association of Scientific

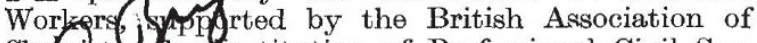
Chefosts the Institution of Professional Civil Servants, the Association of University Teachers, the Physical Society, the Nutrition Society and the Institution of Electronics, held in London during February 15-17, has now been published under the title "Science and Human Welfare"*. The four sessions of the conference dealt successively with science and world needs, the implications of recent scientific development, the responsibilities of men of science in modern society and international organisation of science; the addresses given have been somewhat compressed. It is unfortunate that there is no index or contents page.

In opening the first session, Sir Robert Robinson asserted that while the active help of the Governments is needed, the initiative must come from the men of science. He suggested a start might well be made in the battle against malnutrition and disease, and endorsed the Government's decision not to set up a comprehensive Ministry of Science. Mr. Herbert Morrison said that upon a scientific approach to human problems depends the future of man, and that there has been far too little general appreciation of the value of the scientific method. We need over the whole field of science a combination of freedom, initiative and social responsibility. The position of science in China was described by Dr. T'U Chang Wang, while the needs in South Africa were discussed by Miss P. M. Cooke. Prof. J. M. Burgers dealt with the Dutch scene, M. Mathieu with developments in France, Dr. G. Lathe with Canada and Dr. J. A. Simpson with American views.

At the second session, Dr. S. Taylor discussed trends in medical research, Dr. H. L. Richardson dealt with agriculture, Mr. F. Le Gros Clark with food and famine, Prof. M. L. Oliphant with atomic energy, stressing that the first problem here is the control of the nuclear bomb, and Sir Alfred Egerton with chemical engineering, using penicillin manufacture as an outstanding example. Colonel Ungerson commented on the necessity for collaboration between the nafural scientists and social scientists, and Dr. Bunting on Britain's need for a vast increase in national productivity and the demand for both the highest levels of existing skill and for new kinds of skill.

Opening the third session, Prof. A. V. Hill dealt with the need for men of science to evolve a common standard of ethical behaviour. Prof. B. Farrington, suggesting that science is the main agency in building the human conscience, which is a product of the development of human society, pleaded for the establishment of chairs of history of science. Prof. J. D. Bernal discussed planning and democracy, and said that the most important social responsibility of the

* Science and Human Welfare. Pp. 72. (Temple Fortune Press, Herbal Hill, London, E.C.1.) 2s. 6d. man of science is to be aware of what he is doing and to take part in determining what it is. $\mathrm{He}$ emphasized the importance of free and rapid communication between all branches of science, and of a really efficient organisation for that purpose.

At the final session, Dr. Julian Huxley discussed the organisation and functions of the United Nations Educational, Scientific and Cultural Organisation, and his plea for world co-operation for science was echoed by Dr. Dorothy Needham in dealing with the situation in China, Dr. D. P. Riley as regards France, and Mr. N. S. Bannerjee as regards India. Dr. Ossowski stressed the growing importance of collaboration in the social sciences, especially coordination of research, and Miss L. Ridehatch urged the endowment in Great Britain of more schools of sociology and social science, and greater use of the present theories and findings of social science. Prof. P. M. S. Blackett reviewed the effect of the atomic bomb on the United Nations Organisation and the prospects of control. French views were expressed by Dr. Bonet-Maury and Prof. F. Joliot, while Dr. J. A. Simpson put forward the American views on the possibility of an inspection system.

Sir Robert Watson-Watt, summing up, suggested that the basic prescription is for a fuller and betterbalanced education. While the scientific man must learn more of the humanities and of the similarity of method in the natural and the social sciences, we need to bring the scientific method within the understanding of the ordinary educated person: there is danger that the intentions of Ministers alive to the possibilities of science may be frustrated by misconceptions in the Civil Service. Finally, referring to atomic energy, he emphasized the need for something more than good aspirations in working out the formulæ required to convert the Atomic Energy Commission into an effective force, and in elaborating any system of control and inspection.

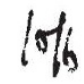

\section{EARLY GREEK SCIENCE}

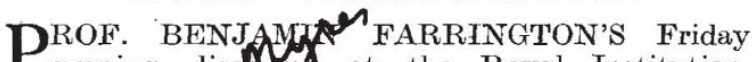
evening piscfurs at the Royal Institution, entitled "Thh Lharacter of Early Greek Science", was deliverod on February 23, 1945, and has recently beef pulfished. It deserves to be widely known; for it corrects some popular misconception, and relates the scientific achievements of early Greeks to their social background. The misconception arose from Aristotle's presentation of the 'physical' philosophers of Ionia as primarily metaphysicians concerned with the general nature of things, and as pioneers in his own line of philosophic thought. Probably even in his time, those early Ionians were represented mainly by summaries of conclusions, without the observations and experiments on which they were founded. But the Ionian objective was more limited, to give "an operational rather than a rational account of the nature of things". Their question was "How it works", and the answer was supplied, not by myths or abstractions, but by practical knowledge within their own control. Thus "technology drove mythology off the field", not indeed from all aspects of Nature, but from those which could be illustrated by the technical equip. ment of the age. Hence the nomenclature and imagery of science, derived from arts and crafts, which Prof. Farrington illustrates from Lucretius, 